\title{
A contratação pública como instrumento para a transparência e concorrência das compras públicas em Portugal
}

\author{
Carla Sofia Alves Lopes ${ }^{1}$ e Ana Lúcia Romão² \\ ${ }^{1}$ Instituto Superior de Ciências Sociais e Políticas, Portugal | csfcal@gmail.com | \\ https://orcid.org/0000-0001-5864-5053 \\ ${ }^{2}$ Centro de Administração e Políticas Públicas; Instituto Superior de Ciências Sociais e \\ Políticas, Portugal | anaromao@iscsp.ulisboa.pt | https://orcid.org/0000-0003-2730-4007
}

Resumo: A atividade contratual pública fomenta o desenvolvimento dos Estados, promovendo a eficiência económica e a promoção do bem social e ambiental. Os contratos públicos são um instrumento de atuação administrativa para satisfazer as necessidades coletivas, mas também um instrumento estratégico para os governos. Este tipo de contratos remete para aquisições económica e socialmente relevantes, interfere na criação de emprego e no incentivo ao investimento, e tem grande relevo no orçamento nacional, representando $4,18 \%$ do PIB português em 2019. O presente estudo visa analisar a contratação pública, na última década, no que concerne à transparência dos procedimentos aquisitivos públicos e à promoção da concorrência entre operadores económicos na prossecução do interesse público. Para prosseguir esta finalidade, recorremos a metodologia qualitativa, que inclu análise documental de relatórios de contratação pública do Instituto dos Mercados Públicos, do Imobiliário e da Construção, e análise de conteúdo do material recolhido através das entrevistas a especialistas em contratação pública. Definimos dimensões de análise, categorizámos dados e criámos unidades de análise, numa matriz de codificação inicial dos dados, sistematizando as entrevistas em unidades de registo. A metodologia qualitativa visa compreender e descrever fenómenos e pode recorrer a perceções e experiências dos participantes para entender as múltiplas realidades. No que respeita aos resultados, a pesquisa permitiu-nos constatar que a transparência dos processos aquisitivos tem vindo a aumentar, havendo, todavia, pontos de melhoria, e que a abertura à concorrência, por parte das entidades adjudicantes, tem tido uma evolução favorável, mas poderá ainda atingir resultados mais elevados, dado verificar-se um recurso excessivo a ajustes diretos. $O$ incremento da concorrência e a maior transparência na utilização do dinheiro público são benefícios da implementação do Código dos Contratos Públicos, impulsionados pela obrigatoriedade de publicitar os contratos públicos no portal BASE e pela contratação pública eletrónica.

Palavras-chave: Concorrência; Contratação Pública; Metodologia Qualitativa; Transparência.

Public Procurement as an Instrument for Transparency and Competition of Public Procurement

Abstract: Public procurement fosters the development of States, promoting economic efficiency and the promotion of social and environmental good. Public procurement is an instrument of administrative action to satisfy collective needs, but also a strategic instrument for governments. This type of contracts refers to economically and socially relevant acquisitions, interferes with job creation and encourages investment, and is highly relevant in the national budget, representing $4.18 \%$ of Portuguese GDP in 2019. The present study intends to analyse public procurement, in the last decade, regarding the transparency of public procurement procedures and the promotion of competition between economic operators in the attainment of the public interest. For this purpose, we use the qualitative methodology, which includes document analysis of public procurement reports from the Institute of Public Procurement, Real Estate and Construction, and content analysis of the material collected through interviews with specialists in public procurement. We defined dimensions of analysis, categorized data and created units of analysis, in an initial data coding matrix, and systematizing the interviews in recording units. The qualitative methodology aims to understand and describe phenomena and can use the participants' perceptions and experiences to understand the multiple realities. Regarding the results, this work made it possible to verify that the transparency of procurement processes has been increasing, however, there are points for improvement, and that the opening to competition, by the contracting entities, has had a favourable evolution, but it can obtain superior results, as there is an excessive use of the direct award. Increased competition and greater transparency in the use of public money are benefits from the implementation of the Public Contracts Code, driven by the obligation to advertise public contracts on the BASE portal and by electronic public procurement.

Keywords: Competition; Public Procurement; Qualitative Methodology; Transparency. 


\section{Introdução}

A atividade contratual pública fomenta o desenvolvimento dos Estados (Matias, 2013) e tem grande impacto no bem-estar dos cidadãos (Anderson \& Yukins, 2008; Matias, 2013). O Estado recorre cada vez mais a particulares para prosseguir o interesse público (Amaral, 2018) e conseguir a melhor qualidade ao melhor preço (Greve, 2008), verificando-se um progressivo aumento da diversidade dos produtos adquiridos e da sofisticação de processos produtivos e tecnologias (Instituto da Construção e do Imobiliário, I.P. [InCl], 2011).

A contratação pública é um instrumento de atuação administrativa para satisfazer as necessidades coletivas, com grande importância nos orçamentos nacionais e europeus (Rodrigues, 2014), representando mais de $16 \%$ do Produto Interno Bruto (PIB) europeu (Maciejewski, Ratcliff \& Blandin, 2020) e 4,18\% do PIB português em 2019 (Instituto dos Mercados Públicos, do Imobiliário e da Construção, I.P. [IMPIC], 2020).

A matéria da contratação pública foi regulada pelo Código dos Contratos Públicos (CCP), aprovado pelo Decreto-Lei n.. 18/2008, que instituiu a obrigatoriedade de realização dos procedimentos concursais em plataformas eletrónicas (InCI, I.P., 2011). Determinou, também, a obrigatoriedade de publicitação dos contratos públicos no portal único da contratação pública (portal BASE), uma ferramenta que possibilita o escrutínio público (InCl, I.P., 2012), criada para ser o repositório da informação pertinente da contratação pública (InCl, 2014).

O CCP foi alterado diversas vezes ao longo dos anos e recentemente republicado pelo Decreto-Lei n. ${ }^{\circ} 111-B / 2017$, com entrada em vigor a 1 de janeiro de 2018. Entre outras alterações, reintroduziu a consulta prévia e reduziu os valores limite para adoção do ajuste direto [artigos 19.\%/c) e d) e 20.\%/1/c) e d) do CCP].

O presente estudo pretende analisar a contratação pública na última década, no que concerne à transparência dos procedimentos aquisitivos públicos e à promoção da concorrência entre operadores económicos na prossecução do interesse público.

Para a sua realização, recorremos a metodologia qualitativa, que inclui análise documental de relatórios de contratação pública do Instituto dos Mercados Públicos, do Imobiliário e da Construção (IMPIC), e análise de conteúdo dos dados recolhidos através das entrevistas a especialistas em contratação pública.

\section{Enquadramento Teórico}

Existem registos de atividade de contratação pública desde a antiguidade (Amaral, 2018; Silva, 2016), mas foi sob influência do New Public Management que se verificou um aumento da contratação de serviços na generalidade das áreas do setor público (Araújo, 2007). A contratação pública tornou-se fundamental na prestação de serviços públicos aos cidadãos e para construir novas infraestruturas (Greve, 2008).

O New Public Management surgiu no início da década de 1980, em sequência das crises petrolíferas iniciadas em 1973, que provocaram elevadas taxas de desemprego e forte inflação nas economias ocidentais (Santos, 2010), para responder à premente necessidade de reduzir os défices públicos (Almodovar, 2002; Araújo, 2000). O seu aparecimento foi influenciado pela combinação de quatro fatores: os difíceis problemas financeiros, o domínio dos ideais neoliberais e progressistas; as soluções imediatas oferecidas pelos grupos de especialistas; e a oportunidade vista pelos chefes políticos (Merrien, 1999).

Este modelo de governação refere-se a um conjunto de ideias e práticas que procuram utilizar abordagens do setor privado no setor público (Bilhim, 2014; Carvalho, 2001; Christensen \& Lægreid, 2011; Denhardt \& Denhardt, 2007; Hyndman \& Lapsley, 2016), destacando a superioridade da gestão privada relativamente à pública (Carvalho, 2001; Ferraz, 2013; Rocha, 2001). Representa ideias e práticas, encaradas como solução para tornar o Estado mais económico, eficiente e eficaz (Hyndman \& Lapsley, 2016). 
Trouxe princípios de externalização, contratualização, descentralização, maior discricionariedade, profissionalismo e mérito na administração pública, maior escolha para os cidadãos, desregulação de setores e avaliação da prestação de serviço (Bilhim, 2014). Caracteriza-se, também, pelo investimento na qualidade e na exploração do potencial das tecnologias de informação e comunicação (Madureira \& Rodrigues, 2006). O New Public Management foi um promotor ao incentivo, comercialização e desagregação (Greve, 2008).

Com o surgimento deste modelo de governação assistiu-se ao incremento do recurso à contratualização (Firmino, 2020) e à privatização, passando o mercado a realizar funções que eram habitualmente desempenhadas pelo Estado (Araújo \& Branco, 2009). A contratação pública tornou-se uma ferramenta importante para orientar o setor público para a competitividade, abertura ao mercado e iniciativa privada na prestação e gestão de serviços públicos (Ferreira \& Amaral, 2013), e as relações hierárquicas entre o poder político e os organismos com a responsabilidade de produzir bens ou prestar serviços diminuíram, estabelecendo-se essencialmente uma relação contratual (Araújo, 2004). Trata-se de uma nova forma de prestar serviços públicos e contribuir para a implementação de políticas públicas (Osborne, 2011).

À medida que a sociedade e as organizações enfrentam novos desafios económicos, sociais e ambientais, a implantação de princípios como transparência, accountability, participação dos cidadãos, e ética têm ganhado peso para melhorar a administração pública (Gözlügöl, 2013).

Nas sociedades democráticas, a Good Governance relaciona-se com o provimento de serviços públicos consoante as necessidades dos cidadãos, atendendo aos recursos existentes (Ferraz \& Alexandre, 2008) e compatibiliza os valores do New Public Management com os de cidadania ativa e participativa, facilitando a formação de novos modelos de administração, que influenciam os resultados das políticas públicas através da atuação dos cidadãos (Bovaird \& Löffler, 2003; Ferraz \& Alexandre, 2008).

A Good Governance inspirou também o discurso neoliberal de modernização nascido do Consenso de Washington, que defendia o papel da economia, eficiência e eficácia do New Public Management, enquanto instrumento de política pública e de transição para uma democracia liberal (Evans, 2012). É a forma como o Estado conduz os assuntos públicos e gere os recursos públicos, para promover o Estado de direito e os direitos humanos (United Nations Office on Drugs and Crime [UNODC], 2020).

Nas últimas décadas, houve um aumento excecional da dimensão e relevância jurídica, económica e social da utilização de contratos públicos na Europa e no mundo (Almeida, 2018), assistindo-se à europeização dos contratos públicos (Dias \& Oliveira, 2010).

O fornecimento dos serviços ao público foi transformado numa coprodução, onde todos os stakeholders têm um papel no desenvolvimento das políticas e serviços públicos (Gözlügöl, 2013).

A atividade contratual pública deixou de ser apenas um meio para assegurar tarefas, como por exemplo a limpeza de uma escola local, para ganhar uma nova agenda (Greve, 2008), envolvendo aquisições com particular relevância económica e social, com impacto na criação de emprego e no incentivo ao investimento (Matias, 2013). É um instrumento que contribui para a realização de políticas públicas, entre as quais políticas ambientais e sociais (Estorninho, 2012; Ferreira \& Amaral, 2013). Tornou-se estratégica para os governos que visam a eficiência económica e a promoção do bem social e ambiental (Ferreira \& Amaral, 2013), assumindo um papel cada vez mais importante na gestão pública, na perspetiva da economia de recursos, e da regularidade financeira e normativa (Teixeira, 2015). É também essencial para o funcionamento eficaz de qualquer organização pública, pois suporta a inclusão das cadeias de fornecimento e a colaboração dos diversos stakeholders com impacto no desempenho das organizações e na criação de valor público (Ferreira \& Amaral, 2013). 


\section{Metodologia}

O objetivo geral do estudo realizado passou por analisar o contributo da contratação pública, na última década, no que concerne à transparência dos procedimentos aquisitivos públicos e à promoção da concorrência entre operadores económicos. Assim, pretendeuse verificar se a contratação pública contribuiu para aumentar a transparência dos processos aquisitivos e avaliar a abertura à concorrência entre agentes económicos nos processos aquisitivos públicos.

No que respeita aos conceitos centrais à investigação, a transparência implica regras procedimentais claras e objetivas e uma publicitação apropriada dos procedimentos contratuais, que permitam aos possíveis interessados determinar em tempo útil se pretendem participar (Pereira, 2013); e a concorrência pressupõe que as entidades adjudicantes utilizam procedimentos abertos, competitivos e concorrenciais, que proporcionam iguais condições de acesso e participação, bem como igual tratamento aos interessados (Gonçalves, 2015).

O modelo de análise assentou nos princípios do modelo de governação New Public Management, que contribuiu para o desenvolvimento da contratação pública, concorrendo por sua vez para o incremento da Good Governance (Fig. 1).

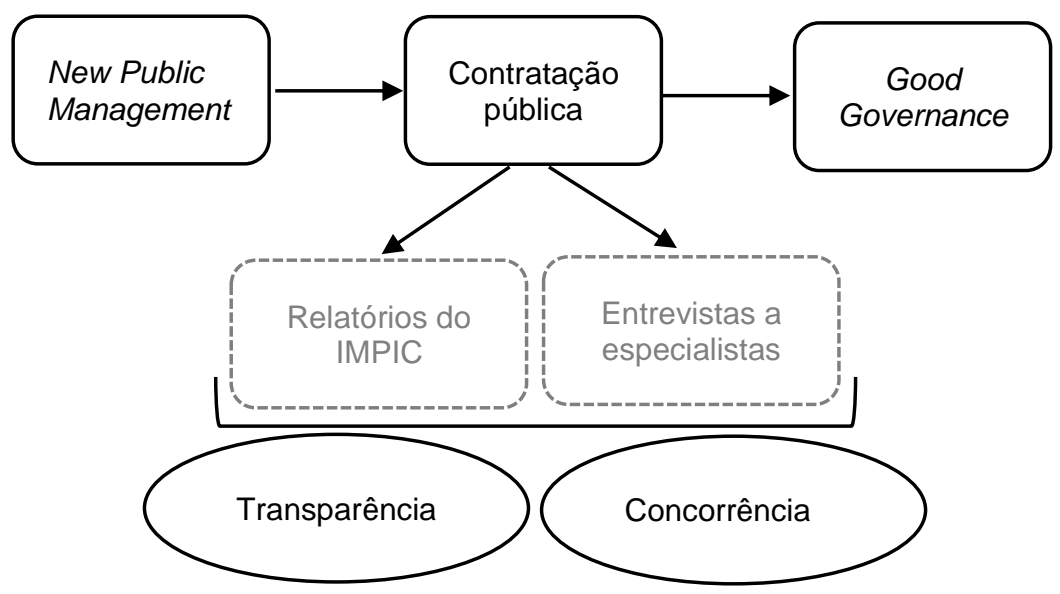

Fig. 1. Modelo de análise. Elaboração própria.

Para a prossecução do estudo recorremos a metodologia qualitativa, que visa compreender e descrever fenómenos (Almeida \& Freire, 2003). Com esta metodologia os investigadores estão particularmente interessados em entender como as coisas ocorrem, podendo recorrer a perceções e experiências dos participantes para entender as múltiplas realidades (Creswell, 2014). A pesquisa qualitativa tem enfoque no processo que está a ocorrer, bem como no produto ou resultado (Creswell, 2014) e foi concebida para atender às diversas necessidades dos diferentes sujeitos, tais como entrevistas qualitativas, focus group, discursos e conversas, e análise de textos e documentos (Walliman, 2011).

A recolha e tratamento de dados foi efetuada através de análise documental e realização de entrevistas, com a respetiva análise de conteúdo.

Destacamos que o IMPIC é o organismo responsável pela regulação dos contratos públicos e a entidade ponto de referência de cooperação com a Comissão Europeia relativamente à contratação pública (artigo 454.--A do CCP), sendo obrigatório as entidades adjudicantes comunicarem-Ihe a informação referente aos contratos públicos (artigo 465.. do CCP). Os dados recolhidos permitiram ao IMPIC elaborar relatórios de contratação pública (InCl, 2011), o que possibilitou a nossa análise documental dos relatórios anuais (2010 a 2019) e das sínteses mensais (2018 e 2019). 
As sínteses mensais foram especialmente consideradas para analisar o impacto da reintrodução da consulta prévia na abertura à concorrência nos processos aquisitivos.

Realizámos, também, entrevistas semiestruturadas a oito especialistas em contratação pública, selecionados entre dirigentes superiores e intermédios da Administração Pública Direta e Indireta, incluindo as entidades que regulam e fiscalizam a contratação pública em Portugal. Os entrevistados qualificados desempenham e/ou desempenharam funções na área da contratação pública no período em análise, e foram identificados com base na pertinência dos seus conhecimentos e da sua experiência na área em estudo, permitindo, assim, uma visão mais transversal e abrangente do fenómeno em estudo.

A elaboração do guião de entrevista atendeu à revisão da literatura efetuada, de modo a sustentar as questões e a validar a sua pertinência com os autores da área científica. Antes da realização das entrevistas foi realizado um pré-teste do guião.

Dado o contexto de pandemia, as entrevistas realizaram-se à distância, através de videoconferência. Tiveram uma duração média de 60 minutos, foram gravadas, após o prévio consentimento dos especialistas entrevistados, e integralmente transcritas.

As respostas foram objeto de análise de conteúdo. Consideramos que esta técnica é adequada para os fins propostos, pois trabalha com informação qualitativa e visa interpretar o seu conteúdo e a expressão do conteúdo, para pôr em evidência os indicadores que possibilitem a inferência sobre uma realidade diferente da realidade da mensagem (Bardin, 2018).

Com base na transcrição das entrevistas e nos objetivos deste estudo criámos as unidades de análise, definimos duas dimensões de análise, sete categorias e 49 subcategorias, numa matriz de codificação inicial dos dados (Tabela ), e sistematizámos as entrevistas em unidades de registo.

Tabela 1. Matriz de codificação inicial dos dados. Elaboração própria.

\begin{tabular}{|c|c|c|}
\hline $\begin{array}{l}\text { Dimensão de } \\
\text { análise }\end{array}$ & Categoria & Subcategoria \\
\hline \multirow{21}{*}{ Transparência } & \multirow{8}{*}{$\begin{array}{l}\text { Clareza das } \\
\text { regras dos } \\
\text { procedimentos } \\
\text { aquisitivos }\end{array}$} & Complexidade dos procedimentos influencia a perceção \\
\hline & & Complexidade das peças procedimentais dificulta a perceção \\
\hline & & Peças procedimentais mal elaboradas dificultam a perceção \\
\hline & & Inexperiência dos recursos humanos dificulta a perceção \\
\hline & & Fraca preparação do tecido empresarial dificulta a perceção \\
\hline & & Equipas qualificadas de empresas especializadas têm boa perceção \\
\hline & & $\begin{array}{l}\text { Uma estratégia de comunicação associada à contratação promove a } \\
\text { perceção }\end{array}$ \\
\hline & & Atualmente a clareza não obsta uma boa contratação pública \\
\hline & \multirow{3}{*}{$\begin{array}{l}\text { Forma de } \\
\text { publicitação dos } \\
\text { procedimentos } \\
\text { aquisitivos }\end{array}$} & Adequada \\
\hline & & Inadequada \\
\hline & & $\begin{array}{l}\text { Melhorar o acesso às peças do procedimento e à estratégia da } \\
\text { compra }\end{array}$ \\
\hline & \multirow{5}{*}{$\begin{array}{l}\text { Tempestividade } \\
\text { da publicitação } \\
\text { dos } \\
\text { procedimentos } \\
\text { aquisitivos }\end{array}$} & Depende da complexidade do objeto aquisitivo \\
\hline & & Adequada \\
\hline & & Inadequada \\
\hline & & $\begin{array}{l}\text { Adequada para operadores económicos dedicados às compras } \\
\text { públicas }\end{array}$ \\
\hline & & $\begin{array}{l}\text { Pouco tempo para operadores económicos recentes nas compras } \\
\text { públicas }\end{array}$ \\
\hline & \multirow{5}{*}{$\begin{array}{l}\text { Evolução da } \\
\text { transparência }\end{array}$} & Houve incremento \\
\hline & & Aumentou no último ano e meio \\
\hline & & Tem de haver um esforço na área da execução dos contratos \\
\hline & & Experiência dos intervenientes - contributo \\
\hline & & Contratação pública eletrónica - ferramenta promotora \\
\hline
\end{tabular}




\begin{tabular}{|c|c|c|}
\hline $\begin{array}{l}\text { Dimensão de } \\
\text { análise }\end{array}$ & Categoria & Subcategoria \\
\hline & & Portal BASE - ferramenta promotora \\
\hline & & Número de pareceres prévios - entrave \\
\hline \multirow{26}{*}{ Concorrência } & \multirow{10}{*}{$\begin{array}{l}\text { Abertura à } \\
\text { concorrência }\end{array}$} & Não houve tendência de maior abertura \\
\hline & & Houve maior abertura \\
\hline & & Contratação pública eletrónica - ferramenta promotora \\
\hline & & $\begin{array}{l}\text { Passagem dos contratos públicos de aprovisionamento para acordos } \\
\text { quadro - mais valia }\end{array}$ \\
\hline & & $\begin{array}{l}\text { Disponibilização gratuita das peças procedimentais - fator } \\
\text { impulsionador }\end{array}$ \\
\hline & & $\begin{array}{l}\text { Reintrodução da consulta prévia - norma incitadora do aumento de } \\
\text { concorrentes }\end{array}$ \\
\hline & & $\begin{array}{l}\text { Imposição de limites ao convite das entidades (ajuste direto) - norma } \\
\text { impulsionadora }\end{array}$ \\
\hline & & Importância das peças procedimentais serem abertas à concorrência \\
\hline & & $\begin{array}{l}\text { Acordos quadro e concursos limitados por prévia qualificação - } \\
\text { restrição }\end{array}$ \\
\hline & & Consulta prévia com um único candidato - limitação \\
\hline & \multirow{9}{*}{$\begin{array}{l}\text { Tipo de } \\
\text { procedimentos } \\
\text { mais utilizados }\end{array}$} & Há dez anos - ajuste direto \\
\hline & & Há cinco anos - ajuste direto \\
\hline & & Atualmente - ajuste direto \\
\hline & & Atualmente - ajuste direto e consulta prévia \\
\hline & & Atualmente - consulta prévia \\
\hline & & Compra ao abrigo de acordo quadro \\
\hline & & Concurso público \\
\hline & & $\begin{array}{l}\text { Consulta prévia e compra ao abrigo de acordo quadro seguem o } \\
\text { ajuste direto }\end{array}$ \\
\hline & & $\begin{array}{l}\text { Consulta prévia e concurso público a crescer desde a republicação } \\
\text { do CCP }\end{array}$ \\
\hline & \multirow{7}{*}{$\begin{array}{l}\text { Evolução da } \\
\text { abertura à } \\
\text { concorrência }\end{array}$} & Positiva \\
\hline & & Negativa \\
\hline & & Aparentemente positiva do ponto vista formal \\
\hline & & Maior número médio de concorrentes \\
\hline & & Revisão aos limiares do ajuste direto (CCP de 2017) - contributo \\
\hline & & Modelos de avaliação nas peças procedimentais - contributo \\
\hline & & Planeamento - contributo \\
\hline
\end{tabular}

Por último, para reforçar a credibilidade e a fiabilidade dos resultados, triangulámos os resultados obtidos na análise documental e nas entrevistas, após a respetiva análise de conteúdo.

\section{Resultados}

\subsection{Transparência dos processos aquisitivos}

É praticamente consensual entre os especialistas (80\%) que a transparência dos processos aquisitivos tem vindo a aumentar na última década, destacando-se o portal BASE e a contratação pública eletrónica como ferramentas de promoção dessa transparência. 
Segundo a informação do IMPIC, registou-se uma tendência de crescimento do número de contratos públicos reportados ao portal BASE entre 2010 e 2017, interrompida em 2018, e retomada em 2019. A tendência crescente ocorreu também no montante contratual, entre 2012 e 2019.

A quebra no número de contratos reportados em 2018, face a 2017, pode ter sido fruto da reintrodução da consulta prévia e da diminuição dos valores limite para adoção do ajuste direto. Esta alteração pode ter levado ao incremento dos procedimentos concorrenciais e da utilização da consulta prévia, ambos procedimentos pré-contratuais com limites de adoção superiores aos do ajuste direto e, por isso, a uma diminuição no número de procedimentos realizados pelas entidades adjudicantes.

Quanto à implementação da contratação pública eletrónica, o Índice de Contratação Pública Eletrónica em Portugal, que visa monitorizar o peso da contratação pública tramitada através de plataformas certificadas (IMPIC, 2019; 2020) registou valores superiores a $60 \%$ entre 2010 e 2019 , e superiores a $70 \%$ em metade dos anos estudados.

Portugal foi, desde cedo, considerado um exemplo a seguir pelos restantes países da União Europeia na contratação pública eletrónica $(\operatorname{InCl}, 2011)$ e o primeiro país na União Europeia a ter um portal eletrónico único da contratação pública (InCl, 2012).

No que concerne aos procedimentos de contratação pública:

- Metade dos especialistas (50\%) considera que os interessados podem ter dificuldades em percecionar as regras dos procedimentos, destacando a complexidade das peças ou a sua má elaboração, a fraca preparação do tecido empresarial ou a baixa experiência dos recursos humanos em compras públicas, como os principais entraves à perceção das regras;

- A maior parte $(78 \%)$ entende que a forma de publicitação dos procedimentos é adequada; e

- Quase metade (44\%) refere que a tempestividade da publicitação dos procedimentos depende da complexidade do objeto aquisitivo - parece ser adequada para os operadores económicos dedicados às compras públicas, mas é pouco tempo para aqueles que começaram recentemente nesta área, e aproximadamente um quarto menciona que os interessados conheceram os procedimentos em tempo útil.

\subsection{Abertura à concorrência nos processos aquisitivos}

Para a generalidade dos especialistas $(75 \%)$ houve incremento da abertura à concorrência por parte das entidades adjudicantes na última década, e indicam a redução dos valores limite para adoção do ajuste direto como contributo para esta abertura à concorrência.

De acordo com a informação do IMPIC, entre 2010 e 2019, o número de ajustes diretos foi sempre superior ao número de procedimentos concorrenciais, apesar dos procedimentos concorrenciais apresentarem uma tendência crescente desde 2011, alcançando o número máximo em 2019.

No montante contratual, os valores registados são mais próximos entre os procedimentos concorrenciais e os ajustes diretos. As Figuras 2 eFig. apresentam o número e montante dos procedimentos contratuais e ajustes diretos. 


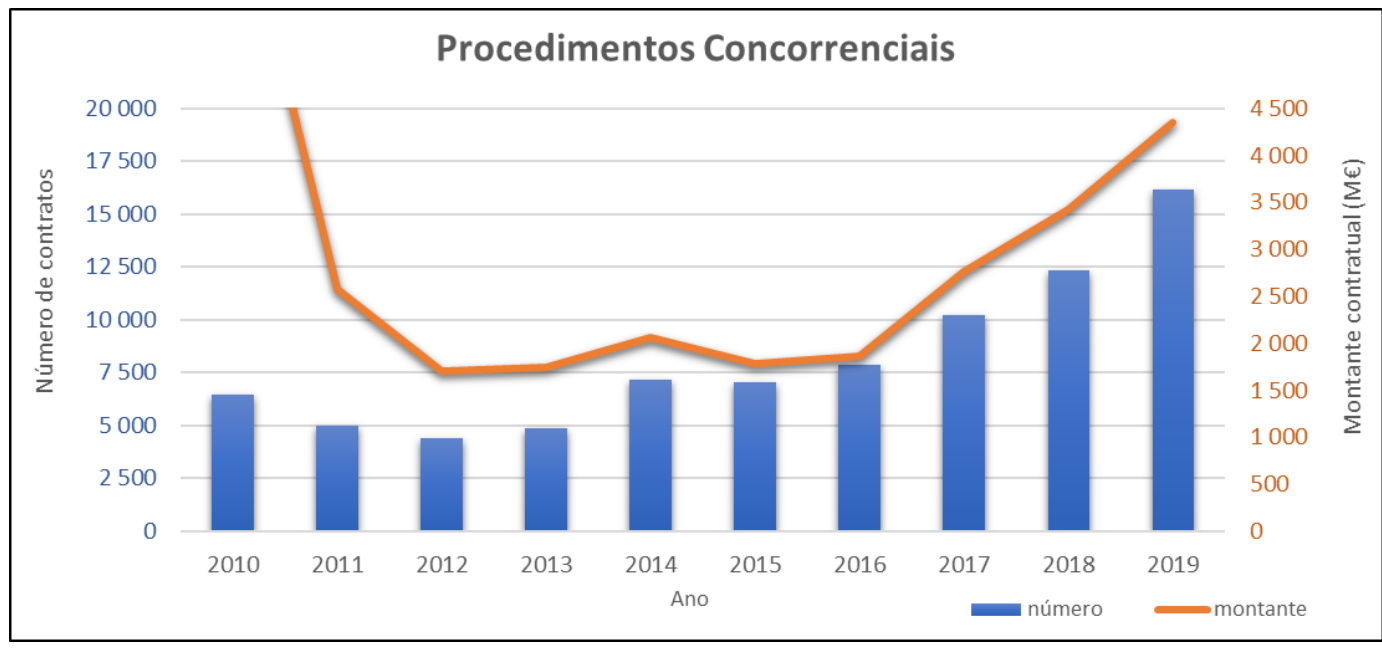

Fig. 2. Número de contratos e montante contratual dos procedimentos concorrenciais. Elaboração própria, a partir da informação das sínteses mensais de contratação pública do IMPIC.

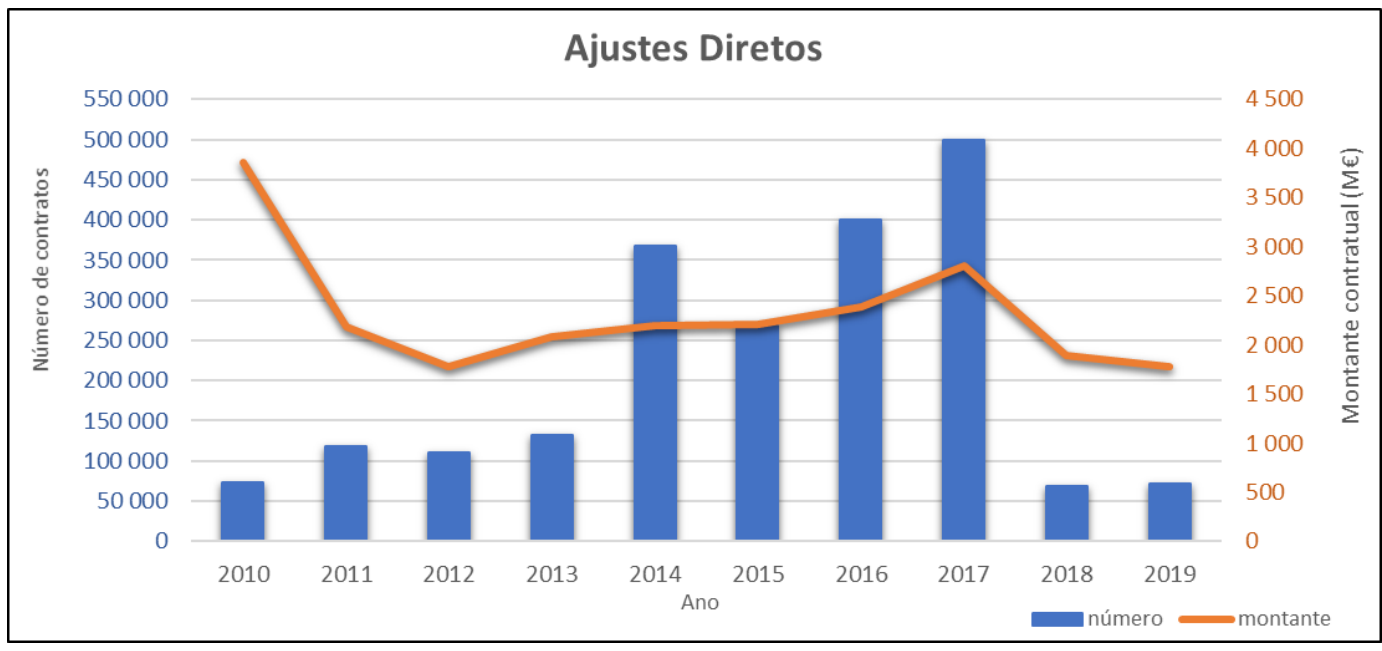

Fig. 3. Número de contratos e montante contratual dos ajustes diretos. Elaboração própria, a partir da informação das sínteses mensais de contratação pública do IMPIC.

A partir de 2013, há referência a outros procedimentos pré-contratuais, que tendencialmente sofrem um incremento em número e montante contratual. Com a reintrodução da consulta prévia e a diminuição dos valores limite para adoção do ajuste direto, o número de ajustes diretos continua a ser o maior, embora os procedimentos concorrenciais e as consultas prévias tenham ganho relevo de 2018 para 2019. Quanto aos montantes contratuais, os procedimentos concorrenciais apresentam os maiores montantes (o que não aconteceu entre 2012 e 2017) e houve um incremento do montante das consultas prévias de 2018 para 2019, enquanto o dos ajustes diretos diminuiu.

Estes resultados vão ao encontro do entendimento da maioria dos especialistas (80\%), que indicam o ajuste direto como o procedimento pré-contratual predominante. A informação do IMPIC e os especialistas estão, também, alinhados na influência positiva das alterações do CCP na abertura à concorrência, pois como aludimos, o número e montante contratual de ajustes diretos decresceu a partir de 2018, enquanto os procedimentos concorrenciais e as consultas prévias cresceram. 
Segundo os especialistas, o incremento da concorrência e a maior transparência na utilização do dinheiro público são benefícios da implementação do CCP, impulsionados pelo cumprimento da obrigatoriedade de publicitar os contratos públicos no portal BASE e pela adoção da contratação pública eletrónica, por parte das entidades adjudicantes.

\section{Conclusões}

Em termos globais apresentamos as principais conclusões deste estudo, relativas à transparência dos processos aquisitivos e à abertura à concorrência por parte das entidades adjudicantes. No que concerne à transparência, os procedimentos de contratação pública são adequadamente publicitados pelas entidades adjudicantes, variando a tempestividade da sua publicitação em função da complexidade do objeto aquisitivo. A compreensão das regras procedimentais é dificultada pela complexidade das peças procedimentais ou má elaboração destas, pela fraca preparação dos operadores económicos nacionais e pela fraca experiência dos recursos humanos em compras públicas. Quanto à concorrência, o ajuste direto é o procedimento pré-contratual preponderante, embora em termos de montante contratual os valores registados estejam mais próximos dos procedimentos concorrenciais. Os procedimentos concorrenciais têm aumentado desde 2018, tanto em número como em montante contratual.

Em suma, podemos afirmar que (i) a transparência dos processos aquisitivos tem vindo a aumentar, sendo necessário, no entanto, que as entidades adjudicantes melhorem as suas peças procedimentais, bem como o tempo de publicitação dos procedimentos de contratação pública; e (ii) houve maior abertura à concorrência por parte das entidades adjudicantes, mas esta poderá ainda ser reforçada, se for reduzido o recurso ao procedimento de ajustes diretos.

\section{Referências}

Almeida, L. S., \& Freire, T. (2003). Metodologias da Investigação em Psicologia e Educação. (3. ${ }^{\mathrm{a}}$ Ed. revista e ampliada). Braga: Psiquilíbrios.

Almeida, M. A. (2018). Teoria Geral do Direito Administrativo. (5. ${ }^{\text {a }}$ Ed. atualizada e refundida). Coimbra: Almedina.

Almodovar, F. (2002). O panorama da gestão de pessoal nos serviços públicos. In E. Quadros (Org.), A Reinvenção da Administração Pública - da burocracia à gestão (pp. 291-306). Lisboa: INA Editora.

Amaral, D. F. (2018). Curso de Direito Administrativo. Vol. II (4. ㄹ Ed.). Coimbra: Edições Almedina, SA.

Anderson, R. D., \& Yukins, C. R. (2008). International Public Procurement Developments in 2008; Public Procurement in a World Economic Crisis. West Government Contracts Year in Review Conference (Covering 2008) 458, 1-15.

Araújo, J. F. (2000). O Modelo de Agência como Instrumento de Reforma da Administração. In J. P. Neto, J. Bilhim, J. D. M. Gonçalves \& E. R. Carvalho (Org.), Forum 2000 - Renovar a Administração. Reforma do Estado e Administração Pública Gestionária (pp. 43-54). Lisboa: Instituto Superior de Ciências Sociais e Políticas.

Araújo, J. F. (2004). A reforma da Gestão Pública: do mito à realidade. Comunicação apresentada no Seminário Internacional Luso-Galaico "A Reforma da Administração Pública: apostas e casos de sucesso", Braga, Portugal.

Araújo, J. F. (2007). Avaliação da Gestão Pública: a Administração Pós Burocrática. Comunicação apresentada na Conferência da UNED, Coruña, Espanha.

Araújo, J. F., \& Branco, J. F. A. (2009). Implementing Performance-Based Management in The Traditional Bureaucracy of Portugal. Public Administration, 87(3), 557-573.

Bardin, L. (2018). Análise de Conteúdo. Coimbra: Edições 70. 
Bilhim, J. A. F. (2014). Ciência da Administração (3. ํㅡ. Ed.). Lisboa: Universidade Aberta.

Bovaird, T., \& Löffler, E. (2003). Evaluating the quality of public governance: indicators, models and methodologies. International Review of Administrative Sciences. 69(3), 313-328.

Carvalho, E. (2001). Reengenharia na Administração Pública: A procura de novos modelos de Gestão. Lisboa. Universidade Técnica de Lisboa - Instituto Superior de Ciências Sociais e Políticas.

Christensen, T., \& Lægreid, P. (2011). Introduction. In T. Christensen \& P. Lægreid (Ed.), The Ashgate Research Companion to New Public Management (pp. 17-32). Surrey: Ashgate Publishing Company.

Creswell, J. W. (2014). Research Design. Qualitative, Quantitative, and Mixed Methods Approaches. (4..$^{\mathrm{a}}$ Ed.). Sage Publications.

Denhardt, J. V. \& Denhardt, R. B. (2007). The new public service: serving, not steering. Expanded Edition. New York: M. E. Sharpe.

Dias, J. E. F., \& Oliveira, F. P. (2010). Noções Fundamentais de Direito Administrativo. (2. ㄹ Ed.). Coimbra: Edições Almedina, SA.

Estorninho, M. J. (2012, abril 27). Green Public Procurement. Por uma contratação pública sustentável. ICJP. https://www.icjp.pt/sites/default/files/media/texto_profa_mje.pdf.

Evans, M. (2012). Beyond the integrity paradox towards 'good enough' governance?. Policy Studies, 33(1), 97-113.

Ferraz, D., \& Alexandre, H. (2008). Que Espaço para uma Cidadania Activa e Participativa no Contexto das Reformas da Administração Pública em Portugal?. Comunicação apresentada no 6ํㅡㄹ Congresso Nacional da Administração Pública, Lisboa, Portugal.

Ferraz, D. (2013). Política, Administração e responsabilização e dirigentes públicos: implicações das teorias, modelos e reformas da Administração. In C. Madureira \& M. Asensio (Org.), Handbook de Administração Pública (pp. 173-185). Lisboa: INA Editora.

Ferreira, I., \& Amaral, L. A. (2013). O potencial endógeno dos contratos públicos eletrónicos nas políticas de modernização da Administração Pública orientadas ao valor público. Comunicação apresentada na 13. a Conferência da Associação Portuguesa de Sistemas de Informação (CAPSI'2013), Évora, Portugal.

Firmino, S. I. R. (2020). Contratualização na administração pública: proposta de um modelo analítico para o desenvolvimento de pesquisas comparadas. Comunicação apresentada no XXV Congreso Internacional del CLAD sobre la Reforma del Estado y de la Administración Pública, Lisboa, Portugal.

Gonçalves, P. C. (2015). Direito dos Contratos Públicos. Coimbra: Almedina.

Gözlügöl, S. V. (2013). Human Being Dignity-Based Public Administration: The Road to Effective Good Governance. The Journal of Faculty of Economics and Administrative Sciences, 18(2), 423-442.

Greve, C. (2008). Contracting for Public Services. London: Routledge.

Hyndman, N., \& Lapsley, I. (2016). New Public Management: The Story Continues. Financial Accountability \& Management, 32(4).

IMPIC. (2019). Contratação Pública em Portugal. Relatório anual 2018. Lisboa: IMPIC.

IMPIC. (2020). Contratação Pública em Portugal 2019. Lisboa: IMPIC.

InCI. (2011). Contratação Pública em Portugal - Relatório Síntese 2010. Lisboa: InCl.

InCl. (2012). Contratação Pública em Portugal 2011. Lisboa: InCl.

InCl. (2014). Contratação Pública em Portugal 2012. Lisboa: InCl.

Maciejewski, M., Ratcliff, C., \& Blandin, L. (2020). Fichas técnicas sobre a União Europeia - 2020. Contratos Públicos. Parlamento Europeu.

Madureira, C., \& Rodrigues. M. (2006). A Administração Pública do século XXI: Aprendizagem organizacional, mudança comportamental e reforma administrativa. Comportamento Organizacional e Gestão. 12(2), 153-171. 
Matias, A. C. C. (2013). Os Princípios Comunitários e a Utilização da Contratação Pública Enquanto Instrumento de Prossecução de Políticas Públicas - Duas Realidades Opostas?. [Dissertação de Mestrado, Universidade Católica Portuguesa]. Repositório Institucional da Universidade Católica Portuguesa. http://hdl.handle.net/10400.14/15036.

Merrien, F. (1999). La Nouvelle Gestion Public: Un Concept Mythique. Lien Social et Politiques. 41, 95-103.

Osborne, S. P. (2011). Public Governance and Public Services: A 'Brave New World' or New Wine in Old Bottles?. In T. Christensen \& P. Lægreid (Ed.), The Ashgate Research Companion to New Public Management (pp. 483-605). Surrey: Ashgate Publishing Company.

Pereira, D. A. (2013). Princípios gerais da contratação pública electrónica. Revista Electrónica de Direito, (2), 1-38.

Rocha, J. A. O. (2001). As Relações entre o Poder Político e os Funcionários. Colóquios sobre o Estatuto dos Funcionários Municipais. Lisboa: CEDEREL.

Rodrigues, C. S. M. (2014). Entre a Contratação Pública Ecológica e a Contratação Pública Sustentável - Compreender o Presente, Transpor o Futuro. [Dissertação de Mestrado, Universidade de Coimbra]. Repositório Institucional da Universidade de Coimbra. http://hdl.handle.net/10316/28443.

Santos, J. Albano. 2010. Finanças Públicas. Oeiras: Ina Editora.

Silva, F. O. (2006). A Regulação dos Contratos Públicos. Coimbra: Almedina.

Teixeira, P. E. G. (2015). Contributos para a Elaboração de um Manual de Procedimentos de Compras Públicas. [Dissertação de Mestrado, Instituto Politécnico do Porto]. Repositório Institucional do Instituto Politécnico do Porto. http://hdl.handle.net/10400.22/7762.

UNODC. (2019, setembro). What is good governance?. https://www.unodc.org/e4j/en/anticorruption/module-2/key-issues/what-is-good-governance.html.

Walliman, N. (2011). Research Methods. The Basics. Routledge.

\subsection{Legislação}

Decreto-Lei n.ำ 18/2008, de 29 de janeiro (Aprova o CCP).

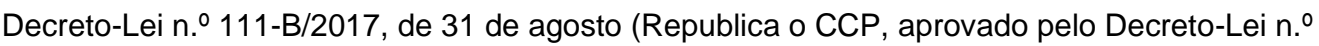
$18 / 2008$, de 29 de janeiro).

\subsection{Páginas oficiais}

Portal Base (http://www.base.gov.pt/Base/pt/Homepage). 